\title{
Enhancement of Microwave Absorption Property of Polymer Blend using MXene
}

\author{
Pritom J Bora and Daniel Q Tan* \\ Technion Israel Institute of Technology and Guangdong Technion Israel Institute of Technology Shantou, China
}

*Corresponding author: Daniel Q Tan, Technion Israel Institute of Technology and Guangdong Technion Israel Institute of Technology Shantou, Guangdong Province, China 515063.
Received Date: January 13, 2020

Published Date: January 21, 2020

\begin{abstract}
2D MXene significantly enhances the microwave absorption properties of a polymer blend (PVB- PEDOT:PSS or PVBPS). For various military and civilian applications such as X-band (8.2-12.4 GHz) and Ku-band (12.4-18 GHz) absorption these materials are very important. The minimum reflection loss (RL)-53 dB was obtained for optimally prepared PVBPS- $\mathrm{Ti}_{3} \mathrm{C}_{2} \mathrm{~T}_{\mathrm{x}}$ MXene nanocomposite for thickness of $1.5 \mathrm{~mm}$. A single $2 \mathrm{~mm}$ thick layer of PVBPS- $\mathrm{Ti}_{3} \mathrm{C}_{2} \mathrm{~T}_{\mathrm{x}}$ MXene nanocomposite shows the most promising absorption bandwidth (RL $\leq-10 \mathrm{~dB}$ from 8.2 to $18 \mathrm{GHz}$ ). Mechanistically, dielectric loss and interfacial polarization contribute more efficiently, and the stored energy becomes predominant in $\mathrm{Ti}_{3} \mathrm{C}_{2} \mathrm{~T}_{\mathrm{x}} \mathrm{MXene}$ contained PVBPS blend which enhances the microwave absorption bandwidth.
\end{abstract}

Keywords: Polymer blend; Polymer nanocomposite; Mxene; Microwave absorption

\section{Introduction}

At present, the cutting edge telecommunication, healthcare systems, detective systems, military applications, etc. predominantly use microwave frequency [1-3]. The lightweight polymer nanocomposite microwave absorbing materials is increasingly felt due to the presence of electromagnetic threat [34]. Polyvinyl butyral (PVB) based blend and nanocomposite has drawn special attraction for organic nanoelectronics as well as for microwave absorption due to many advantages such as lightweight, weather resistive, solution processability (facile coating), lower cost [2-6]. Two-dimensional (2D) nano materials are among the most promising materials for electromagnetic/device applications due to the better control of their properties at the atomic scale with high surface to volume ratio. A large family of 2D metal carbides and nitrides, called MXenes, have been proposed as one of the attracting absorption predominant electromagnetic interference (EMI) shielding materials particularly in microwave regions due to its light weight, superior electrical property and microstructure [78]. MXenes have a general formula of $M_{n+1} X_{n}$, where $M$ represents a transition metal such as $\mathrm{Ti}, \mathrm{Zr}, \mathrm{Hf}, \mathrm{V}, \mathrm{Nb}, \mathrm{Ta}, \mathrm{Cr}$, Mo, and $\mathrm{X}$ is carbon or nitrogen, and $n=1-3$. The surface terminations, such as oxygen, fluorine, hydroxyl, always present on MXene surface, and they can be shown as $T_{x}$ in the $M_{n+1} X_{n} T_{x}$ formula [7-8]. The objective of this short communication is to investigate the microwave absorption property of facile prepared dielectric polymer blend (PVBPEDOT:PSS) incorporated with $\mathrm{Ti}_{3} \mathrm{C}_{2} \mathrm{~T}_{\mathrm{x}}$ MXene.

\section{Results and Discussion}

The $\mathrm{Ti}_{3} \mathrm{C}_{2} \mathrm{~T}_{\mathrm{x}}$ MXene was synthesized by the standard synthesis method [8], as shown by the schematic of the process in Figure 1 (a). The recorded FESEM images were shown in the Figure 1(bc). The facile preparation of PVB-PEDOT:PSS (PVBPS) blend was reported in our previous article [9]. In order to prepare MXene loaded PVBPS, $\mathrm{Ti}_{3} \mathrm{C}_{2} \mathrm{~T}_{\mathrm{x}}$ MXene was first dispersed in deionized water with a concentration $1 \mathrm{mg} / \mathrm{ml}$. The $\mathrm{Ti}_{3} \mathrm{C}_{2} \mathrm{~T}_{\mathrm{x}}$ MXene suspension was then optimally added ( $3 \mathrm{ml})$ to the PVBPS solution $(10 \mathrm{ml})$ followed by casting on a PET mold and drying for $24 \mathrm{~h}$ in open air (Figure 2).

The microwave absorption is understood in terms of reflection loss (RL), as given by Refs. [4-6],

$$
R L(d B)=20 \log \left|\frac{z_{\text {in }}-z_{0}}{z_{\text {in }}+z_{0}}\right|
$$

Where, $\mathrm{Z}_{0}(=377 \Omega)$ is the free space intrinsic impedance and Material impedance, 


$$
z_{i n}=z_{0} \sqrt{\frac{\mu_{r}}{\varepsilon_{r}}} \tanh \left(j \frac{2 \pi f d \sqrt{\mu_{r} \varepsilon_{r}}}{c}\right)
$$

Where, $\varepsilon_{r}\left(\varepsilon_{r}=\varepsilon^{\prime}-i \varepsilon^{\prime}\right)$ and $\mu_{r}\left(\mu_{r}=\mu^{\prime}-i \mu^{\prime}\right)$ is the relative permittivity and permeability respectively. $\mathrm{f}$ is the frequency; $\mathrm{d}$ is the thickness of the composite material and $\mathrm{c}$ is the velocity of light.
The RL value of $-10 \mathrm{~dB}$, which corresponds to $90 \%$ absorption, is adequate for practical applications [9]. The RL of PVBPS blend was shown in Figure 2(a). The bandwidth for RL $\leq-10 \mathrm{~dB}$ of PVBPS blend was not found to increase significantly until the thickness was increased to $2 \mathrm{~mm}$. Better RL was observed for Ku-band (12.4$18 \mathrm{GHz}$ ) for a thickness of $1.5 \mathrm{~mm}$. On the other hand, outstanding RL value of $-53 \mathrm{~dB}$ was achieved for the

(a)
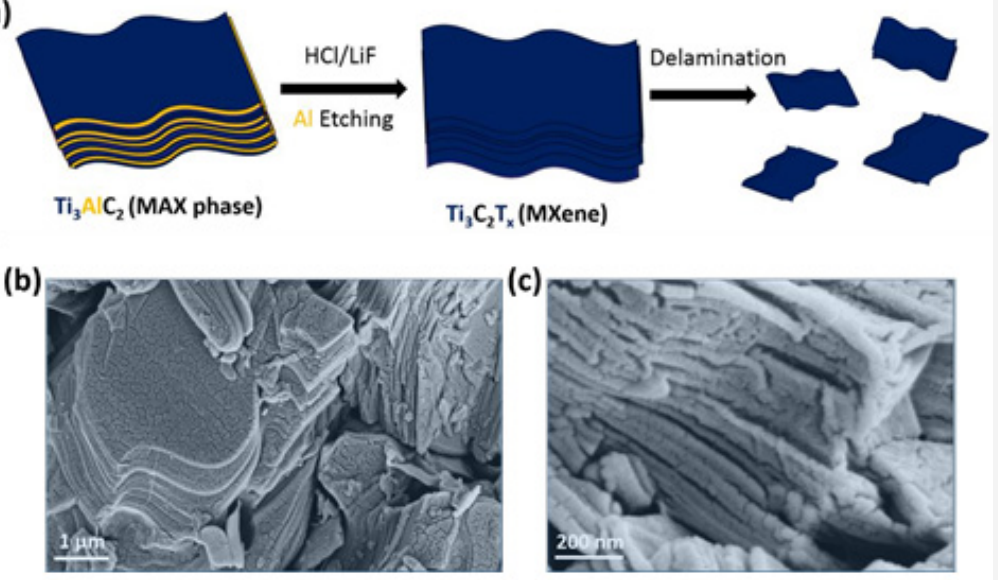

Figure 1: (a) Schematic of Ti3C2Tx MXene synthesis, (b-c) recorded SEM images of synthesized MXene.
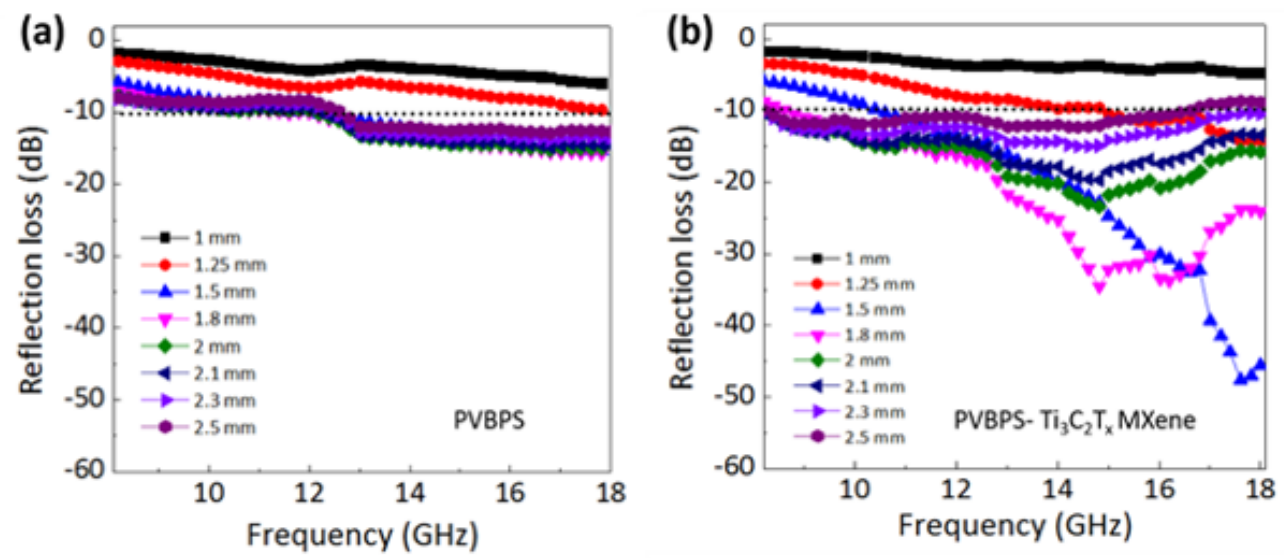

Figure 2: Reflection loss (RL) of (a) PVBPS and (b) PVBPS- $\mathrm{Ti}_{3} \mathrm{C}_{2} \mathrm{~T}_{\mathrm{x}} \mathrm{MXene}$ nanocomposite in the frequency range 8.2-18 GHz..

PVBPS- $\mathrm{Ti}_{3} \mathrm{C}_{2} \mathrm{~T}_{\mathrm{x}}$ MXene nanocomposite for the thickness of 1.5 $\mathrm{mm}$ as shown in Figure 2 (b). For thickness of $1.8 \mathrm{~mm}$, a broad absorption bandwidth of $8.5-18 \mathrm{GHz}$ was achieved with minimum RL value - $35 \mathrm{~dB}$. When thickness was increased to $2 \mathrm{~mm}$, the absorption bandwidth of PVBPS- $\mathrm{Ti}_{3} \mathrm{C}_{2} \mathrm{~T}_{\mathrm{x}}$ MXene nanocomposite was found to increase 8.2-18 GHz (entire X-band and Ku-band). Thus, this work clearly demonstrates the enhancement of microwave absorption properties of PVBPS blend (in a much broader bandwidth) with the presence of $\mathrm{Ti}_{3} \mathrm{C}_{2} \mathrm{~T}_{\mathrm{x}}$ MXene. Mechanistically, dielectric loss and interface polarizations contribute more efficiently. This is because the charges in the interfaces in PVBPS- $\mathrm{Ti}_{3} \mathrm{C}_{2} \mathrm{~T}_{\mathrm{x}}$ MXene (either heterogeneous or homogeneous interface) can generate aggregation and the rearrangement. As a result, the polarization loss takes place, which has a significant impact on dielectric loss [10-11]. In addition, the associated functional groups of $\mathrm{Ti}_{3} \mathrm{C}_{2} \mathrm{~T}_{\mathrm{x}}$
MXene could generate dipolar interactions at multiple interfaces, and form capacitor-like structures [10-11]. Thus, it gave rise to an excellent electromagnetic energy absorption performance.

\section{Conclusion}

In the development of microwave absorption material, the use of $2 \mathrm{D}$ materials as a component in optimized polymer blends is a promising approach, as demonstrated by enhanced microwave absorption bandwidth in PVBPS- $\mathrm{Ti}_{3} \mathrm{C}_{2} \mathrm{~T}_{\mathrm{x}}$ MXene nanocomposite. A large bandwidth, 8.2-18 GHz, was achieved for the optimally prepared PVBPS- $\mathrm{Ti}_{3} \mathrm{C}_{2} \mathrm{~T}_{\mathrm{x}}$ MXene nanocomposite for the single 2 mm thick layer. The minimum RL value of $-53 \mathrm{~dB}$ was achieved for $1.5 \mathrm{~mm}$ thick PVBPS- $\mathrm{Ti}_{3} \mathrm{C}_{2} \mathrm{~T}_{\mathrm{x}}$ MXene nanocomposite. PVBPS$\mathrm{Ti}_{3} \mathrm{C}_{2} \mathrm{~T}_{\mathrm{x}}$ MXene nanocomposite may present a tangible pathway for developing extremely efficient microwave absorption material in 
future.

\section{Acknowledgment}

Authors would like to thank Prof. Praveen C Ramamurthy (Dept. of Materials Engineering, IISc) and Prof. KJ Vinoy (Dept. of Electrical and Communication Engineering, IISc, India) for providing the lab facilities for microwave measurements and characterizations.

\section{Conflict of Interest}

No conflict of interest.

\section{References}

1. Wang L, Chen L, Song P, Liang C, Lu Y, et al. (2019) Fabrication on the annealed $\mathrm{Ti}_{3} \mathrm{C}_{2} \mathrm{~T}_{\mathrm{x}}$ MXene/Epoxy nanocomposites for electromagnetic interference shielding application. Compos Part B Eng 171: 111-118.

2. Bora PJ, Mallik N, Ramamurthy PC, Kishore, Madras G (2016) Poly(vinyl butyral) -polyaniline-magnetically functionalized fly ash cenosphere composite film for electromagnetic interference shielding. Compos Part B Eng 106: 224-233.

3. Bora PJ, Azeem I, Vinoy KJ, Ramamurthy PC, Madras G (2018) Morphology controllable microwave absorption property of polyvinylbutyral (PVB)$\mathrm{MnO}_{2}$ nanocomposites. Compos Part B Eng 132: 188-196.

4. Bora PJ, Porwal M, Vinoy KJ, Kishore, Ramamurthy PC, et al. (2018) Industrial waste fly ash cenosphere composites based broad band microwave absorber. Compos Part B Eng 134: 151-163.
5. Bora PJ, Porwal M, Vinoy KJ, Ramamurthy PC, Madras G (2016) Influence of $\mathrm{MnO}_{2}$ decorated $\mathrm{Fe}$ nano cauliflowers on microwave absorption and impedance matching of polyvinylbutyral (PVB) matrix. Mater Res Express 3(9): 095003.

6. Bora PJ, Harstad SM, Gupta S, Pecharsky VK, Vinoy KJ, et al. (2019) Gadolinium silicide $\left(\mathrm{Gd}_{5} \mathrm{Si}_{4}\right)$ nanoparticles for tuneable broad band microwave absorption. Mater Res Express 6(5): 055053.

7. Anasori B, Lukatskaya MR, Gogotsi Y (2017) 2D metal carbides and nitrides (MXenes) for energy storage. Nat Rev Mater 2: 16098.

8. Shahzad F, Alhabeb M, Hatter CB, Anasori B, Man Hong S, et al. (2016) Electromagnetic interference shielding with 2D transition metal carbides (MXenes). Science 353(6304): 1137-1140.

9. Bora PJ, Gupta S, Pecharsky VK, Vinoy KJ, Ramamurthy PC, et al. (2019) Enhancement of microwave absorption bandwidth of polymer blend using ferromagnetic gadolinium silicide nanoparticles. Mater Lett 252 178-181.

10. Cao M, Shu J, Wang X, Wang Xi, Zhang M, et al. (2019) Electronic Structure and Electromagnetic Properties for 2D Electromagnetic Functional Materials in Gigahertz Frequency. Ann Phys 531(4): 1800390.

11. Han M, Yin X, Wu H, Hou Z, Song C, et al. (2016) $\mathrm{Ti}_{3} \mathrm{C}_{2}$ MXenes with Modified Surface for High-Performance Electromagnetic Absorption and Shielding in the X-Band. ACS Appl Mater Interfaces 8(32): 21011-21019. 